Targeting bone and fat with novel exercise for peripubertal boys:

\title{
The CAPO Kids trial
}

Short title: Exercise, bone and fat in boys

Conflict of interest: The authors have no conflicts of interest to disclose.

Financial Disclosure: The authors have no financial relationships relevant to this article to disclose.

External Funding: No external funding was secured for this study.

Conflicts of interest: The authors have no conflicts of interest to disclose. 


\section{ABSTRACT}

2 To test the effect of a brief, novel bone- and fat-targeted exercise program on bone, muscle

3 and fat in healthy pre and peripubertal boys. We conducted a 10-min, 3/wk capoeira and

4 jumping exercise intervention for 9 months with year 5 and 6 school boys. Anthropometrics,

5 maturity, heart rate, blood pressure, maximal vertical jump, aerobic capacity and calcaneal

6 broadband ultrasound attenuation and stiffness index (BUA and SI; Achilles, GE) were

7 assessed. Bone, lean and fat tissue (DXA; XR800, Norland), and parameters of bone

8 geometry (pQCT, ХСТ3000, Stratec) were measured from a subsample of 36 boys.

9 Of 188 boys (10.6 $\pm 0.5 \mathrm{yr})$ who consented, 172 completed all testing; 104 exercisers (EX) and

1068 controls (CON). $30 \mathrm{EX}$ and 6 CON participants underwent DXA and pQCT measures.

11 EX improved BUA (+4.3\% vs. $+2.1 \%, p=0.035)$, waist circumference $(+2.8 \%$ vs. $+6.2 \%$,

$12 p=0.001)$, heart rate $(-5.3 \%$ vs. $+1.5 \%, p=0.005)$, maximal vertical jump $(+12.2 \%$ vs. $-0.3 \%$,

$13 p=0.001)$ and estimated maximal oxygen consumption $(+9.1 \%$ vs. $+1.2 \%, p=0.001)$

14 compared to CON. Three 10-min sessions of capoeira and jumping per week improved

15 calcaneal bone and metabolic health of pre and peripubertal boys over the course of a school

16 year with little disruption to the academic schedule.

17 Key words: bone; lean mass; obesity; pediatric; exercise; physical activity. 


\section{INTRODUCTION}

It is well recognized that childhood and adolescence represent critical periods for bone growth (50). It is also known that excess body fat accumulated in youth typically tracks into adulthood, leading to increased risk of chronic metabolic diseases (9, 39). In light of the important positive influence of exercise on both bone and fat tissue (33), childhood is considered something of a "window of opportunity" to apply physical activity to enhance bone and prevent the accumulation of excess fat to secure lifelong health benefits $(8,15)$. Currently however, worldwide, most children do not meet Australia’s Physical Activity and Sedentary Behaviour Guidelines for healthy levels of physical activity in youth nor the American College of Sports Medicine Physical Activity Guidelines (2, 36). The situation likely contributes to the increased prevalence of overweight children, and an associated increased risk of developing metabolic diseases and sustaining fractures in youth and later life $(5,44)$. Increasing physical activity levels of children not currently meeting the guidelines is an obvious but challenging solution to a growing public health crisis. Opportunity and inclination are the primary obstacles to widespread adoption of increased childhood physical activity, and important targets for encouraging greater engagement, thus appealing activities that are easily incorporated into the school routine should be identified.

Brief, rapid, high impact, weight bearing exercise is the most osteogenic $(11,12)$. By contrast, sustained low impact aerobic exercise is typically recommended to reduce or prevent overweight, and resistance training most effectively improves lean mass. The disparity between exercise recommendations for the skeletal and metabolic systems has created challenges for holistic exercise prescription. However, only a small degree of creativity is required to develop activities that incorporate elements of each form of training, and novel programs can be particularly appealing to children. Nevertheless, to date, no 
42 researchers have attempted combination exercise interventions specifically to target bone and

43 fat for kids.

44 Although women are at greatest risk of osteoporosis (21), there is also a strong relationship between bone mineral density and risk of fracture in men. Moreover, men suffer a higher risk of mortality after hip fractures than women (4). Although it has not yet been fully established

47 if fractures in old age can be prevented by enhancing bone in youth, there is evidence to suggest it may be the case $(13,49)$. Thus, increasing levels of exercise of growing boys would be a strategy to reduce the burden of morbidity and mortality of male osteoporosis in the aging population $(12,24)$.

51 The aim of the current study then, was to test the efficacy of a brief, novel and enjoyable

52 bone- and fat-targeted exercise program on parameters of bone, muscle and fat in healthy pre and peripubertal boys over the course of a school year. We hypothesized that the exercise group would experience greater improvements in parameters of bone, muscle and fat than age-matched controls.

\section{METHODS}

\section{Participants}

58 One hundred and eighty-nine boys enrolled in years 5 and 6 at two local primary schools

59 (Gold Coast, Queensland, Australia) were initially included in the study. Students were 60 excluded if they: were taking medications known to affect bone, muscle or metabolism; had

61 limb injuries or been immobilized in the previous six months; or had any condition not

62 compatible with a 10-minute bout of moderate to vigorous physical activity.

63 Ethical approval was obtained from Griffith University Human Research Ethics Committee

64 (PES/25/11/HREC). As both schools chose to incorporate the CAPO Kids activities 
65 (exercises and/or testing) into their curriculum (irrespective of our study), all students performed the specific activities delivered at each school. We requested consent from the children to include their data from the testing activities in our analysis and all children did so.

Parents were requested to decline to consent if they did not wish their child's data to be included in the study analysis. The parents of only a single student from the control school declined to consent.

\section{Experimental design}

A nine-month, cluster controlled trial was designed to address our hypotheses. The two participating schools were randomly assigned to control (CON) or exercise (EX) sites by a coin toss. The EX school adopted a 10-minute exercise intervention as part of its daily class schedule on three consecutive days each week and sessions took place every week of the school year with the exception of scheduled holidays. The aim of the intervention activities was to target multiple physiological systems to improve indices of cardiovascular and metabolic health, body composition and physical performance, with minimal disruption to the daily class schedule. Testing took place at baseline (T0, Feb/2012) and follow-up (T9, Dec/2012).

\section{School-based exercise intervention}

The intervention program was fundamentally based on capoeira, a Brazilian sport that contains mixed elements of martial arts and dance. Capoeira movements were supplemented with a combination of medium to high impact manoeuvres intended to load the upper and lower limbs. Each exercise bout was led by a single instructor (RN), and comprised 10 minutes of continuous high intensity movements. All exercise sessions were held during school hours, before lunch break for Year 5 participants $(n=57)$ and after lunch break for Year $6(n=50)$. Each session was led by a single investigator $(R N)$. Up to three classroom 
teachers were present to provide general supervision. Activities in each session varied from day to day, however each was composed of several high impact movements, such as repetitive jumps and hops (with maximal effort) combined with capoeira-specific movements (with an emphasis on high speed execution) (Table 1). Initially (first two months), a typical session was composed of learning how to perform the ginga, followed by around 60 jumps, 20 kicks and 15 cartwheel and handstand practice. Repetition and intensity was progressively increased over the course of the year, such that a typical session in the final stages would entail a warm up with the ginga, followed by an average of 120 jumps, 30 kicks and 20 to 30 inverted movements such as handstands or cartwheels. Children were occasionally given small prizes such as sports balls and game vouchers to reward participation and performance.

\section{Control group activities}

Control school participants took part in baseline and follow up testing under the guise of an educational activity to learn about measures of health. Otherwise, CON boys participated in their usual school activities across the course of the year, unaware of the exercise activities carried out at the intervention school or the overall purpose of the study. The control school was well-matched to the intervention school in terms of student demographics, school fees, school hours, teacher-student ratio, and usual physical education regime.

\section{Data collection}

Anthropometrics, physical performance measures, and measures of bone, muscle and fat were performed at baseline (T0) and follow up (T9). The majority of measures were taken during physical education (PE) classes (i.e. anthropometrics, metabolic and physical performance measures, and calcaneal ultrasound measures), and a small subset of participants attended the Griffith University’s Bone Densitometry Research Laboratory for dual-energy x-ray absorptiometry (DXA) and peripheral quantitative computed tomography (pQCT) measures. 


\section{Anthropometrics}

114 Height and sitting height were measured using a portable stadiometer (HART Sport and

115 Leisure, Brisbane, Queensland, Australia) and a $50 \mathrm{~cm}$ flat stool, while body weight was

116 measured in kg using digital scales (Soehnle, Hamburg, Switzerland). Waist circumference

117 was measured using an anthropometric tape measure (Lufkin Executive Thinline, Apex,

118 USA). The tape was positioned at the mid-point between the margin of the lowest pair of ribs

119 and the iliac crest, taken at the end of gentle expiration (51). Neither weight, nor waist

120 circumference were divulged to participants at the time of testing.

121 Maturity assessment

122 Years from the age of peak height velocity (YAPHV) were estimated using the algorithm 123 developed by Mirwald and colleagues (31) to provide a marker of biological maturity. The

124 algorithm incorporates sex, age, height, sitting height and weight in order to predict the

125 timing of peak height velocity based on regression data from a large pediatric longitudinal 126 trial.

\section{Performance measures}

128 Maximal vertical jump height was used as an index of lower limb muscle power using a

129 Yardstick device (Swift Performance Equipment, Brisbane, Queensland, Australia). The

130 height of a standing reach was recorded with the participant standing with feet shoulder-

131 width apart, shoulders level, and preferred arm raised with extended elbow, wrist and fingers.

132 After a practice attempt, five jumps for maximal height were performed in countermovement

133 fashion without arm swing to touch the highest possible peg on the Yardstick. Maximal

134 vertical jump height was determined as the difference between the height of a standing reach

135 and the best total jump height. 
136 Aerobic capacity was determined using a 20-metre shuttle-run test, from which maximal 137 oxygen consumption $\left(\mathrm{VO}_{2}\right.$ max) was estimated using the algorithm $\mathrm{VO}_{2}$ max $=31.025+$ $(3.238 \times$ velocity $)-(3.248 \times$ age $)+(0.1536 \times$ age $\times$ velocity $)(16)$. As described by Léger

139 (16), participants ran between two points marked on the ground 20 meters apart. A pre140 recorded audible tone sounded at progressively shorter intervals to determine lap speed.

141 Once the participant was unable to meet the required speed on successive laps, the number of 142 his/her level was recorded and the associated velocity was entered into the algorithm along 143 with age to estimate $\mathrm{VO}_{2} \max (\mathrm{ml} / \mathrm{kg} / \mathrm{min})$.

\section{Cardiovascular measures}

145 Resting heart rate (beats/min) and resting blood pressure (mmHg) were measured using standard procedures. A single investigator $(\mathrm{RN})$ measured heart rate from the radial pulse 147 after the participant had rested for 15 minutes in the supine position. Systolic and diastolic brachial blood pressures were measured from the left arm of each participant while in the seated position. A stethoscope, sphygmomanometer and inflatable cuff were used to detect the first and fifth Korotkoff sounds per usual practice (52).

\section{Lifestyle measures}

Physical activity participation and dietary calcium intake were estimated using validated questionnaires. The bone-specific physical activity questionnaire (BPAQ) was used to quantify bone-relevant physical activity participation (46). Participants were asked to record all regular physical activities they have participated in during their life and to indicate the years when participation took place. Participants additionally recorded the type and frequency of all current physical activities (i.e. previous 12 months). Total BPAQ score was calculated by using current and past BPAQ scores, which were calculated from questionnaire responses with an on-line calculator (http://www.fithdysign.com/BPAQ/). Intraclass 
correlation coefficients (ICC) for intra- and interoperator reliability for the BPAQ have previously been reported as $0.93,0.97$ and 0.97 , and $0.86,0.93$ and 0.92 , respectively for current, previous and total BPAQ-derived physical activity scores (48).

Daily dietary calcium intake was estimated using the Australian Child and Adolescent Eating Survey food frequency questionnaire (ACAES) (45). The questionnaire is composed of 120 items relating to diet, and 15 additional questions about age, vitamin use and sedentary behaviour. Participants were asked to complete the questionnaire during class time, based on food intake in the previous three days. The self-administered questionnaire is validated for Australian children from nine to sixteen years old. Completed questionnaires were computer analysed remotely per the questionnaire guidelines.

\section{Bone and body composition measures}

Quantitative ultrasonometry (Lunar Achilles ${ }^{\mathrm{TM}}$ Insight, GE) was employed to determine broadband ultrasound attenuation (BUA) (dB/MHz) and stiffness index (SI) (\%) of the calcaneus. Least significance change (LSC) for BUA and SI from a subsample ( $\mathrm{n}=10)$ of repeated QUS measures (with repositioning) was calculated to account for measurement error. BUA LSC was $6.27 \mathrm{~dB} / \mathrm{MHz}$ and SI LSC was $2.77 \%$.

The subgroup that participated in testing at the bone densitometry research laboratory were examined by DXA (XR800, Norland Medical Systems, USA) to estimate bone mineral content (BMC) and density (BMD) of the whole body (WB), lumbar spine (LS) and nondominant hip (femoral neck, FN; and trochanter, TR). Estimates of lean and fat tissue mass were also determined from whole body scans. Additional parameters of bone strength were calculated from BMD measures, including material stiffness (E), bone structural strength (IBS), and cross-sectional moment of inertia (CSMI), as previously described (41). pQCT (XCT-3000, Stratec Medizintechnik GmbH, Pforzheim, Germany) was used to determine 
bone strength measures of the non-dominant tibia (at 4 and 38\% sites) and radius (at 4 and 66\% sites), including: total content, total density, total area, trabecular content, trabecular density, trabecular area, total and trabecular bone strength index (BSI) at 4\% sites, and cortical content, cortical density, cortical area, cortical thickness, cross-sectional area (CSA), periosteal and endosteal perimeters at the proximal (38 and 66\% sites).

\section{Statistical analyses}

Between-group differences at baseline were examined using one-way ANOVA, while intervention effects were determined using two-way ANOVA controlling for weight, maturity, baseline values, physical activity and calcium consumption. Both per protocol and intention to treat (ITT) analyses were conducted.

In order to ensure adequate statistical power, an a priori power analysis was undertaken based on the bone measure with the largest precision error (i.e. BUA) using previously observed between-group effects (49). Accordingly, we required a total of 142 participants to observe a mean difference between groups of $4 \mathrm{~dB} / \mathrm{MHz}$ with a standard deviation of 12 $\mathrm{dB} / \mathrm{MHz}$, assuming $80 \%$ power with an alpha level of 0.05 . All statistical analyses were performed with SPSS version 21.0 for Windows (IBM, Chicago, IL, USA).

\section{RESULTS}

\section{Participants}

From 189 eligible participants, consent was obtained for 188 boys (109 EX and 79 CON). The majority (96\%) of the participants were Caucasian while the remainder were Asian. Of those, 183 completed baseline testing (T0) and 172 participated in follow up testing (T9). Two boys from EX did not attend baseline testing, and three did not attend follow up, resulting in 104 boys included in EX for analysis. One CON participant's parent did not 
consent to use of their child's data in our analysis. An additional three CON boys did not attend baseline testing and eight did not attend follow up testing, leaving 68 boys in CON for analysis (Figure 1). As results of per protocol (data not shown) and intention to treat analyses were essentially the same, we elected to report ITT findings unless otherwise indicated. Overall, data from 172 boys were included in the ITT analysis, representing 91\% of the original consenting cohort.

At baseline, both groups exhibited similar characteristics for the majority of measures. EX exhibited slightly lower scores than CON however, for total BPAQ score (19.4 \pm 13.6 vs. $25.4 \pm 21.3, p=0.039)$; resting blood pressure (76.1 \pm 7.1 vs. $77.9 \pm 7.2 \mathrm{mmHg}, p=0.001)$; and estimated $\mathrm{VO}_{2} \max (28.65 \pm 6.84$ vs. $33.35 \pm 7.11 \mathrm{ml} / \mathrm{kg} / \mathrm{min}, p=0.001)$. EX exhibited similar scores for BUA (97.2 \pm 9.8 vs. $93.9 \pm 10.8 \mathrm{~dB} / \mathrm{MHz}, p=0.088)$ and YAPHV $(-2.9 \pm$ 0.8 years vs. $-2.7 \pm 0.6$ years, $p=0.065$ ) (Table 2 ). Any differences were managed by controlling for baseline values in the analysis of treatment effects.

Age, calcium and other physical and performance variables at baseline were not different. In the subgroup (EX: 30; CON: 6), no differences were found in DXA and pQCT variables at baseline.

\section{Change in physical and performance outcomes}

Following the nine-month intervention, EX exhibited more favourable change than CON in waist circumference ( $+2.8 \%$ vs. $+6.2 \%, p=0.001$; $95 \%$ CI 1.7 to $3.9 \%$ vs. 4.6 to $9.0 \%)$, resting heart rate $(-5.3 \%$ vs. $+1.5 \%, p=0.002$; $95 \%$ CI -6.7 to $-3.8 \%$ vs. -4.6 to $7.6 \%)$, vertical jump (+12.2\% vs. $-0.3 \%, p<0.001$; $95 \%$ CI 9.3 to $18.4 \%$ vs. -2.7 to $4.1 \%)$, and estimated $\mathrm{VO}_{2} \max (+9.1 \%$ vs. $+1.2 \%, p<0.001$; $95 \%$ CI 6.4 to $13.2 \%$ vs. -0.7 to $5.2 \%$ ) (Table 2). After controlling for baseline values, YAPHV and weight, those findings 
230

231

232

233

234

235

236

237

238

239

240

241

242

243

244

245

246

247

248

249

250

251

252

remained the same. There were no significant between-group differences in change for any other physical or performance parameters.

\section{Change in bone outcomes}

A significant between-group difference in change was observed for bone parameters (Table 2 and 3). Specifically, EX improved calcaneal BUA more than CON based on ITT analyses ( $+4.3 \%$ vs. $+2.1 \%, p=0.001 ; 95 \%$ CI 2.4 to $7.1 \%$ vs. 0.6 to $4.1 \%)$ and per protocol analyses $(p=0.035)$.

From the subgroup of participants who underwent bone densitometric measures, only LS E improved more for EX than CON (+14.2\% vs. +1.5\%, $p=0.039$; $95 \%$ CI 10.4 to $20.4 \%$ vs. 4.9 to $7.6 \%$ ). Although not statistically significant, a trend for reductions in fat in the EX group compared to CON (-3.5\% vs. $+7.7 \%, p=0.074$; $95 \%$ CI -7.8 to $1.8 \%$ vs. $-3.5-18.1 \%)$ was observed. There were no between-group differences in any pQCT-derived tibial parameters. At the radius, however, periosteal circumference at the $66 \%$ site increased more for EX than CON (+9.2\% vs. $+4.8 \%, p=0.030$; $95 \%$ CI 8.5 to $15.1 \%$ vs. -1.3 to $18.1 \%$ ) and a trend for greater improvements for EX than CON in cortical area at the 66\% site was evident (+12.4\% vs. $+7.7 \%, p=0.083$; $95 \%$ CI 6.0 to $19.7 \%$ vs. -8.9 to $14.5 \%)$. No other significant between-group differences were observed in changes in bone geometry, volumetric density or strength parameters from pQCT.

\section{Compliance}

Mean intervention compliance was $90 \%$ with absence from school accounting for all missed sessions. Student relocation and absence from school on follow-up testing days contributed to an overall loss to follow-up of $8.5 \%$. Only one relatively minor adverse event took place when an intervention participant inadvertently made contact with another participant during a 
handstand maneuver. Other than the discomfort experienced at the time of the incident, there was no ongoing pain or injury.

\section{DISCUSSION}

The current intervention trial was designed to be a brief, engaging, school-based exercise intervention to improve parameters of musculoskeletal and cardiovascular health in pre and early pubertal boys, without notably disrupting a primary school schedule. The intervention improved a number of parameters of bone health and important metabolic characteristics.

\section{Intervention effects on bone}

We based our intervention activity on previous reports that 10 to 12 minutes of weight bearing impact exercises are sufficient to stimulate bone responses in children $(7,25,27,32$, 33, 49). Our findings are in accord with reports that 10-minute bouts of moderately high impact exercise can improve bone health specifically in pre and peripubertal boys (20, 26, 27). The $2 \%$ between-group difference observed in calcaneal BUA also aligns with a previous observation that 8-months of 10-minute jumping twice per week improves BUA of adolescent boys (49).

An observed $12.7 \%$ increase in lumbar spine stiffness, and 4.4\% improvement in periosteal circumference at the radius are also suggestive of meaningful exercise-related change at clinically relevant sites, however we note that only a sub-sample of the study cohort was able to attend the bone densitometry research laboratory for on-site testing and so power was very low for those analyses. Our lack of ability to detect broader findings in other DXA- and pQCT-derived outcomes may similarly reflect constraints of statistical power. By contrast, our ability to measure calcaneal BUA from the entire sample, owing to the portable nature of the QUS device, provided adequate power to detect significant effects of the exercise 
intervention on BUA. While some investigators have reported that a 10-minute jumping program applied three times per week for 7 months improved FN BMC and LS BMC and BMD in prepubertal children (boys and girls combined) (7), others have reported a only limited effect of exercise on BMD in pediatric cohorts. For instance, 20 months of 10-minute high impact exercises improved FN BMC but no other bone parameter of prepubertal boys (27), and a twice weekly jumping intervention improved only FN area of male adolescents after 8 months (49).

The upper extremity loading included in the current intervention is novel. Traditionally bone-targeted exercise interventions overlook the upper extremity in lieu of weight bearing activities designed to load the sites of greatest clinical relevance to osteoporosis - the spine and hip. However, some evidence exists to suggest that children with low bone mass are more susceptible to upper extremity fractures, and since bone response to mechanical loading is site-specific, upper extremity loading may be clinically beneficial in youth $(5,10)$. Furthermore, distal radial fractures are the source of considerable morbidity and cost in older individuals with osteoporosis (40). Our findings that the CAPO Kids intervention improved periosteal circumference of the radius and tended to improve radius cortical area is therefore noteworthy. It is possible that the non-weight-bearing skeleton is more sensitive to weight bearing loading than regular weight-bearing bones (35). By contrast, we did not detect exercise-induced changes in pQCT-derived parameters of bone geometry at the tibia. Similarly, others have reported that twelve weeks of 25 daily jumps from a box did not improve any pQCT tibia measurements of children and adolescents aged 3 to 18 (combined boys and girls) (14). However, others have reported that a 16 month jumping program (3min/day of counter-movement jumping, three times per day) increased tibial BSI of pre and early pubertal boys (23). In light of the prolonged period required for bone to respond and adapt to mechanical interventions, it is reasonable to assume the former study (12 weeks) 
301 (14) was of inadequate duration to detect an effect on parameters of tibial geometry if there 302 was one. Our intervention was of adequate duration, but likely underpowered for most pQCT 303 outcomes.

304 High-impact intervention and lean mass

305 Although high-impact exercise interventions are typically designed specifically to stimulate 306 bone responses, fat and lean mass are frequently also measured $(6,12,19,22,27,30,49)$. 307 Those trials have reported a variety of effects of high-impact exercise on lean and fat mass;

308 likely a function of differences between interventions. Notably, previous bone-targeted 309 exercise interventions have effected either no change (22, 29, 30), or only small 310 improvements in the lean mass of pediatric cohorts (33), and our findings are no different. 311 As an 8-month, twice-weekly jumping program for adolescents increased lean mass of boys by $4.9 \%$, we suggest the lack of effect is related to maturation (47). There is considerable evidence in other literature to suggest that even targeted muscle training will not markedly increase lean mass in prepubertal children $(28,38)$. Those comments notwithstanding, on occasion lean mass improvements have been observed in prepubertal children. For instance, a 20-month high-impact circuit intervention (12 min, three times per week) improved lean mass of prepubertal boys by $4.2 \%$ (27).

318 Although change in bone and muscle mass are not always observed following exercise intervention, cross-sectional data indicates that muscle mass is the most important predictor of bone size in boys $(3,18,42)$. While an association of bone mass and muscle mass is suggestive that the latter may be beneficial to the former, it is not possible to assume

322 causality when there are common genetic determinants of both lean tissues. 
324 A recent observation that bone-targeted exercise interventions likely reduce fat in pediatric

325 cohorts (33) is supported by the current findings. Waist circumference, which is a good

326 predictor of visceral abdominal adiposity, is closely associated with obesity $(17,34)$. The

327 increase in waist circumference we observed in both groups was to be expected in our

328 growing pediatric cohort, however, our observation that the control group increased waist

329 circumference more than the exercise group over the course of a year suggests that the

330 intervention effectively minimised the accumulation of abdominal adipose tissue. In

331 addition, our observation that in the subgroup, the control group gained nearly $8 \%$ body fat

332 while the exercise group lost 3.5\% (NS), supports the potential positive effect of our exercise 333 intervention on adiposity.

\section{High-impact exercise and performance}

335 The current intervention activities improved estimated $\mathrm{VO}_{2}$ max (from the 20 m shuttle run)

336 and maximum jump height. It is commonly held that aerobic and continuous exercises are

337 the best activities to improve $\mathrm{VO}_{2}$ max and resting heart rate (37), however our data show

338 brief high-impact exercise is also effective. Given the emphasis on high-velocity execution

339 of movements in our intervention (including jumps), it is perhaps not surprising that

340 maximum jump height improved in the exercise group. Although we did not perform motion

341 analyses, it is reasonable to assume that components of co-ordination and neuromuscular

342 adaptations may have contributed to jump performance in addition to muscle strength.

\section{$343 \quad$ Limitations}

344 The low number of participants in the subsample who were able to attend testing at the Bone

Densitometry Research Laboratory reduced our ability to detect between-group differences in 
emptively included BUA as our primary bone outcome measure in light of the fact that it could be measured in-school using a portable QUS device. We therefore were able to obtain from all participants an index of bone strength, that is comparable to DXA and pQCT in its ability to monitor bone densitometric change in children $(1,43)$, to achieve sufficient statistical power to examine our primary outcome measure. The intervention school had a slightly larger student cohort than the control school, which we acknowledge may also have created a sampling bias.

\section{CONCLUSION}

Osteoporosis and metabolic diseases benefit from exercise intervention and early application is likely to be especially beneficial. Opportunity and inclination are the primary obstacles to widespread adoption of increased childhood physical activity, such that enjoyment and inschool programs are important engagement strategies. Our novel, enjoyable exercise intervention was easily incorporated into the primary school setting and improved indices of calcaneal bone and metabolic health in pre and early pubertal boys. Given the provocative preliminary findings at the radius, there is a compelling need for additional pQCT studies in larger cohorts of children that examine the effects of this unique exercise regimen on bone health at the distal forearm. 


\section{REFERENCES}

1. Alwis G, Rosengren B, Nilsson JÅ, Stenevi-Lundgren S, Sundberg M, Sernbo I, et al. Normative calcaneal quantitative ultrasound data as an estimation of skeletal development in swedish children and adolescents. Calcified Tissue International. 2010;87(6):493-506.

2. American College of Sports Medicine. Physical fitness in children and youth. Med Sci Sports Exerc. 1988;20(4):422-3.

3. Baptista F, Barrigas C, Vieira F, Santa-Clara H, Homens PM, Fragoso I, et al. The role of lean body mass and physical activity in bone health in children. J Bone Miner Metab. 2012;30(1):100-8.

4. Center JR, Nguyen TV, Schneider D, Sambrook PN, Eisman JA. Mortality after all major types of osteoporotic fracture in men and women: An observational study. Lancet. 1999;353(9156):878-82.

5. Clark EM, Ness AR, Bishop NJ, Tobias JH. Association between bone mass and fractures in children: A prospective cohort study. J Bone Miner Res. 2006;21(9):1489-95.

6. Fuchs R, Cusimano B, Snow CYF. Box jumping: A bone-building exercise for elementary school children. J Phys Ed, Recreation \& Dance. 2002;73(2).

7. Fuchs RK, Bauer JJ, Snow CM. Jumping improves hip and lumbar spine bone mass in prepubescent children: A randomized controlled trial. J Bone Miner Res. 2001;16(1):148-56. 8. Going SB, Farr JN. Exercise and bone macro-architecture: Is childhood a window of opportunity for osteoporosis prevention? Int J Body Compos Res. 2010;8:13.

9. Gortmaker SL, Swinburn BA, Levy D, Carter R, Mabry PL, Finegood DT, et al. Changing the future of obesity: Science, policy, and action. Lancet. 2011;378(9793):838-47. 
10. Goulding A, Grant AM, Williams SM. Bone and body composition of children and adolescents with repeated forearm fractures. J Bone Miner Res. 2005;20(12):2090-6. Epub 2005/11/19.

11. Heinonen A, Sievänen H, Kannus P, Oja P, Pasanen M, Vuori I. High-impact exercise and bones of growing girls: A 9-month controlled trial. Osteoporos Int. 2000;11(12):1010-7. 12. Hind K, Burrows M. Weight-bearing exercise and bone mineral accrual in children and adolescents: A review of controlled trials. Bone. 2007;40(1):14-27.

13. Jackowski SA, Kontulainen SA, Cooper D, Lanovaz JL, Beck TJ, Baxter JA. Adolescent physical activity and bone strength at the proximal femur in adulthood. Med Sci Sports Exerc. 2013.

14. Johannsen N, Binkley T, Englert V, Neiderauer G, Specker B. Bone response to jumping is site-specific in children: A randomized trial. Bone. 2003;33(4):533-9.

15. Khan K, McKay HA, Haapasalo H, Bennell KL, Forwood MR, Kannus P, et al. Does childhood and adolescence provide a unique opportunity for exercise to strengthen the skeleton? J Sci Med Sport. 2000;3(2):150-64.

16. Léger LA, Mercier D, Gadoury C, Lambert J. The multistage 20 metre shuttle run test for aerobic fitness. J Sport Sci. 1988;6(2):93-101.

17. Li C, Ford ES, McGuire LC, Mokdad AH. Increasing trends in waist circumference and abdominal obesity among us adults. Obesity. 2007;15(1):216-.

18. Lima F, De Falco V, Baima J, Carazzato JG, Pereira RMR. Effect of impact load and active load on bone metabolism and body composition of adolescent athletes. Medicine \& Science in Sports \& Exercise. 2001;33(8):1318-23.

19. Linden C, Ahlborg HG, Besjakov J, Gardsell P, Karlsson MK. A school curriculumbased exercise program increases bone mineral accrual and bone size in prepubertal girls: 
Two-year data from the pediatric osteoporosis prevention (pop) study. J Bone Miner Res. 2006;21(6):829-35.

20. Linden C, Alwis G, Ahlborg H, Gardsell P, Valdimarsson O, Stenevi-Lundgren S, et al. Exercise, bone mass and bone size in prepubertal boys: One-year data from the pediatric osteoporosis prevention study. Scand J Med Sci Spor. 2007;17(4):340-7.

21. Loprinzi PD, Cardinal BJ. Interrelationships among physical activity, depression, homocysteine, and metabolic syndrome with special considerations by sex. Prev Med. 2012;54(6):388-92.

22. Macdonald HM, Kontulainen S, Petit M, Beck T, Khan K, McKay H. Does a novel school-based physical activity model benefit femoral neck bone strength in pre- and early pubertal children? Osteoporos Int. 2008;19(10):1445-56.

23. Macdonald HM, Kontulainen SA, Khan KM, McKay HA. Is a school-based physical activity intervention effective for increasing tibial bone strength in boys and girls? J Bone Miner Res. 2007;22(3):434-46.

24. MacKelvie KJ, Khan KM, McKay HA. Is there a critical period for bone response to weight-bearing exercise in children and adolescents? A systematic review. Br J Sports Med. 2002;36(4):250-7.

25. MacKelvie KJ, Khan KM, Petit MA, Janssen PA, McKay HA. A school-based exercise intervention elicits substantial bone health benefits: A 2-year randomized controlled trial in girls. Pediatrics. 2003;112(6):e447-e52.

26. MacKelvie KJ, McKay HA, Petit MA, Moran O, Khan KM. Bone mineral response to a 7-month randomized controlled, school-based jumping intervention in 121 prepubertal boys: Associations with ethnicity and body mass index. J Bone Miner Res. 2002;17(5):83444. Epub 2002/05/15. 
27. MacKelvie KJ, Petit MA, Khan KM, Beck TJ, McKay HA. Bone mass and structure are enhanced following a 2-year randomized controlled trial of exercise in prepubertal boys. Bone. 2004;34(4):755-64.

28. Malina RM. Weight training in youth-growth, maturation, and safety: An evidencebased review. Clin J Sport Med. 2006;16(6):478-87.

29. McKay HA, MacLean L, Petit M, MacKelvie-O'Brien K, Janssen P, Beck T, et al. "Bounce at the bell": A novel program of short bouts of exercise improves proximal femur bone mass in early pubertal children. Br J Sports Med. 2005;39(8):521-6. Epub 2005/07/28. 30. McKay HA, Petit MA, Schutz RW, Prior JC, Barr SI, Khan KM. Augmented trochanteric bone mineral density after modified physical education classes: A randomized school-based exercise intervention study in prepubescent and early pubescent children. J Pediatr. 2000;136(2):156-62.

31. Mirwald RL, Baxter-Jones AD, Bailey DA, Beunen GP. An assessment of maturity from anthropometric measurements. Med Sci Sports Exerc. 2002;34(4):689-94.

32. Morris FL, Naughton GA, Gibbs JL, Carlson JS, Wark JD. Prospective ten-month exercise intervention in premenarcheal girls: Positive effects on bone and lean mass. $\mathrm{J}$ Bone Miner Res. 1997;12(9):1453-62. Epub 1997/09/01.

33. Nogueira RC, Weeks BK, Beck B. Exercise to improve pediatric bone and fat: A systematic review and meta-analysis. Med Sci Sports Exerc. 2014;46(3):610-21.

34. Onat A, Barlan M, Uyarel H, B Uzunlar VS. Measures of abdominal obesity assessed for visceral adiposity and relation to coronary risk. Int J Obesity. 2004;28(8):1018-25.

35. Ozcivici E, Garman R, Judex S. High-frequency oscillatory motions enhance the simulated mechanical properties of non-weight bearing trabecular bone. Journal of Biomechanics. 2007;40(15):3404-11. 
36. Parrish XJ, Brown M, Emmel J, Marino N. A systematic review to inform the australian sedentary behaviour guidelines for children and young people. Australian Government Department of Health. 2013.

37. Pate RR, Pratt M, Blair SN, Haskell WL, Macera CA, Bouchard C, et al. Physical activity and public health: A recommendation from the centers for disease control and prevention and the american college of sports medicine. J Am Med Assoc. 1995;273(5):4027.

38. Payne VG, Morrow Jr JR, Johnson L, Dalton SN. Resistance training in children and youth: A meta-analysis. Res Q Exercise Sport. 1997;68(1):80-8.

39. Perrin JM, Bloom SR, Gortmaker SL. The increase of childhood chronic conditions in the united states. J Am Med Assoc. 2007;297(24):2755-9.

40. Riggs BL, Melton Iii L. The worldwide problem of osteoporosis: Insights afforded by epidemiology. Bone. 1995;17(5):S505-S11.

41. Sievänen H, Kannus P, Nieminen V, Heinonen A, Oja P, Vuori I. Estimation of various mechanical characteristics of human bones during dual energy x-ray absorptiometry: Methodology and precision. Bone. 1996;18(1):S17-S27.

42. Vicente-Rodríguez G. How does exercise affect bone development during growth? Sports med. 2006;36(7):561-9.

43. Wang Q, Nicholson PH, Timonen J, Alen M, Moilanen P, Suominen H, et al. Monitoring bone growth using quantitative ultrasound in comparison with dxa and pqct. Journal of Clinical Densitometry. 2008;11(2):295-301.

44. Wang Y, Lobstein T. Worldwide trends in childhood overweight and obesity. International Journal of Pediatric Obesity. 2006;1(1):11-25. 
45. Watson JF, Collins CE, Sibbritt DW, Dibley MJ, Garg ML. Reproducibility and comparative validity of a food frequency questionnaire for australian children and adolescents. Int J Behav Nutr Phy. 2009;6(1):1-17.

46. Weeks BK, Beck BR. The bpaq: A bone-specific physical activity assessment instrument. Osteoporos Int. 2008;19(11):1567-77. Epub 2008/04/17.

47. Weeks BK, Beck BR. Twice-weekly, in-school jumping improves lean mass, particularly in adolescent boys. Pediatr Obes. 2012;7(3):196-204.

48. Weeks BK, Hirsch RD, Moran D, Beck B. A useful tool for analysing the effects of bone-specific physical activity. Salud Cienc. 2011;18(6):538-42.

49. Weeks BK, Young CM, Beck BR. Eight months of regular in-school jumping improves indices of bone strength in adolescent boys and girls: The power pe study. J Bone Miner Res. 2008;23(7):1002-11.

50. Whiting SJ, Vatanparast H, Baxter-Jones A, Faulkner RA, Mirwald R, Bailey DA. Factors that affect bone mineral accrual in the adolescent growth spurt. J Nutr. 2004;134(3):696S-700S.

51. WHO. Measuring obesity-classification and description of anthropometric data: Copenhagen, denmark. National Food and Nutrition Institute. 1989.

52. Williams L, Wilkins. Best practices: Evidence-based nursing procedures: Lippincott Williams \& Wilkins; 2007. 
TABLE 1: DESCRIPTIONS OF INTERVENTION ACTIVITIES

\begin{tabular}{|c|c|}
\hline Activity & Description \\
\hline Jumps & Two-leg take off, followed by a two-leg landing; \\
\hline Hops & Single-leg take off, followed by a single-leg landing on the same side; \\
\hline Tuck-jumps & $\begin{array}{l}\text { Double-leg jump, with hips and knees flexed during flight, bringing the knees into close proximity to the chest, and arms } \\
\text { momentarily holding the knees when they reach the chest; }\end{array}$ \\
\hline Jump-squats & Double-leg jump, where the start and final position is with hips and knees flexed to approximately 90 degrees; \\
\hline Star jumps & $\begin{array}{l}\text { With feet together, jumping and positioning legs apart, at the same time the arms go up touching the hands above the head, and } \\
\text { returning to the initial position, continuously; }\end{array}$ \\
\hline Jump-lunges & $\begin{array}{l}\text { Taking a large step forward so that the knee is flexed to } 90 \text { degrees as a start position, jumping while swapping legs, returning to } \\
\text { start position with the opposite leg; }\end{array}$ \\
\hline Ginga & $\begin{array}{l}\text { Feet positioned shoulder-width apart, and then one foot is placed behind on the ball of the foot. The back foot returns to the initial } \\
\text { position, and the other is placed back, imagining that a triangle is being drawn on the floor with the feet; }\end{array}$ \\
\hline Handstands & $\begin{array}{l}\text { From ginga, the hands are placed on the ground shoulder-width apart and the legs up, together, open or even with one leg } \\
\text { forwards; }\end{array}$ \\
\hline Cartwheels & Traditional movement, but performed slowly and with arms and legs slightly flexed; \\
\hline Bênção with jumps & $\begin{array}{l}\text { Starts from the ginga position. A straight forward push kick is performed, with the ankle dorsi-flexed before returning to the base } \\
\text { position. }\end{array}$ \\
\hline
\end{tabular}


TABLE 2: BASELINE AND NINE-MONTH MEASURES ( \pm SD) WITH PERCENT CHANGE AND 95\% CONFIDENCE INTERVAL IN PHYSICAL AND LIFESTYLE CHARACTERISTICS (N = 172).

\begin{tabular}{|c|c|c|c|c|c|c|c|c|c|}
\hline \multirow{2}{*}{ Parameter } & \multicolumn{4}{|c|}{ Control $(n=68)$} & \multicolumn{4}{|c|}{ Intervention $(n=104)$} & \multirow[b]{2}{*}{$\mathbf{p}$} \\
\hline & Baseline & Follow up & $\%$ & $95 \% \mathrm{CI}$ & Baseline & Follow up & $\%$ & $95 \% \mathrm{CI}$ & \\
\hline Age (years) & $10.7(0.6)$ & $11.4(0.6)$ & 6.5 & $(6.4-6.6)$ & $10.5(0.5)$ & $11.3(0.5)$ & 7.6 & $(7.4-7.8)$ & 0.106 \\
\hline YAPHV (years) & $-2.7(0.6)^{\dagger}$ & $-2.2(0.6)$ & -18.5 & $(-22.3--16.4)$ & $-2.9(0.5)^{\dagger}$ & $-2.3(0.6)$ & -20.7 & $(-23.4--19.3)$ & $0.001^{*}$ \\
\hline Weight (kg) & $39.6(9.2)$ & $42.9(9.8)$ & 8.5 & $(6.6-11.5)$ & $38.7(8.8)$ & $41.7(10.2)$ & 7.8 & $(5.7-10.6)$ & 0.487 \\
\hline Standing height (m) & $1.437(0.062)$ & $1.477(0.067)$ & 2.8 & $(2.3-3.2)$ & $1.441(0.0)$ & $1.478(0.078)$ & 2.6 & $(2.3-2.8)$ & 0.990 \\
\hline Sitting height (m) & $0.742(0.032)$ & $0.756(0.031)$ & 1.9 & $(1.5-2.5)$ & $0.735(0.032)$ & $0.758(0.036)$ & 3.1 & $(2.6-3.4)$ & 0.807 \\
\hline Waist circumference (cm) & $67.7(10.8)$ & $71.9(10.5)$ & 6.8 & $(4.6-9.0)$ & $67.0(9.0)$ & $68.8(9.1)$ & 2.8 & $(1.7-3.9)$ & $0.001^{*}$ \\
\hline Resting heart rate (beats/min) & $69(2)$ & $70(2)$ & 1.5 & $(-4.6-7.6)$ & $71(6)$ & $67(6)$ & -5.3 & $(-6.7--3.8)$ & $0.002^{*}$ \\
\hline Blood pressure (mmHg) & $78(7)^{\dagger}$ & $76(6)$ & -2.3 & $(-4.1--0.4)$ & $74(10)^{\dagger}$ & $72(9)$ & -3.2 & $(-4.5--1.0)$ & 0.998 \\
\hline Vertical jump (cm) & $31(5)$ & $31(5)$ & -0.3 & $(-2.7-4.1)$ & $30(5)$ & $34(5)$ & 12.2 & $(9.3-18.4)$ & $0.001 *$ \\
\hline Estimated $\mathrm{VO}_{2} \max (\mathrm{ml} / \mathrm{kg} / \mathrm{min})$ & $33(7)^{\dagger}$ & $34(6)^{* *}$ & 1.2 & $(-0.7-5.2)$ & $29(7)^{\dagger}$ & $31(7)^{* *}$ & 9.1 & $(6.4-13.2)$ & $0.001 *$ \\
\hline BUA (dB/MHz) & $97.2(9.3)^{\dagger}$ & $99.1(8.6)$ & 2.1 & $(0.6-4.1)$ & $93.9(9.9)^{\dagger}$ & $97.7(9.6)$ & 4.3 & $(2.4-7.1)$ & $0.001^{*}$ \\
\hline SI (\%) & $79.2(8.4)$ & $83.1(9.1)$ & 4.9 & $(3.2-7.2)$ & $79.1(9.0)$ & $84.6(9.2)$ & 7.2 & $(5.4-9.8)$ & 0.059 \\
\hline
\end{tabular}

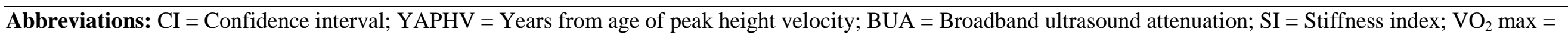
maximal oxygen consumption. P values represent between-group comparisons of percent change.

$*=\mathrm{p} \leq 0.05 ; \uparrow=\mathrm{p} \leq 0.05$, Difference between groups at baseline; $* *=\mathrm{p} \leq 0.05$, Difference between groups at follow up. 
TABLE 3: BASELINE AND NINE-MONTH MEASURES ( \pm SD) WITH PERCENT CHANGE AND 95\% CONFIDENCE INTERVAL IN DXA MEASURES $(\mathrm{N}=36)$

\begin{tabular}{|c|c|c|c|c|c|c|c|c|c|}
\hline \multirow{2}{*}{ Parameter } & \multicolumn{4}{|c|}{ Control (n = 6) } & \multicolumn{5}{|c|}{ Intervention $(n=30)$} \\
\hline & Baseline & Follow up & $\%$ & $95 \%$ CI & Baseline & Follow up & $\%$ & $95 \% \mathrm{CI}$ & $\mathbf{p}$ \\
\hline Lean mass (Kg) & $29.7(7.1)$ & $32.2(9.6)$ & 8.4 & $(-3.5-18.1)$ & $25.7(4.0)$ & $28.0(4.6)$ & 9.3 & $(7.5-11.1)$ & 0.974 \\
\hline Fat mass (Kg) & $17.3(10.6)$ & $18.7(12.3)$ & 7.7 & $(2.9-12.8)$ & $13.3(6.9)$ & $12.8(6.8)$ & -3.5 & $(-7.8-1.8)$ & 0.074 \\
\hline WB BMC (g) & 1769.25 (423.77) & 1943.00 (543.97) & 9.8 & $(1.9-16.2)$ & 1573.17 (312.06) & $1683.11(455.19)$ & 7.0 & $(-1.8-12.5)$ & 0.278 \\
\hline WB BMD (g) & $0.765(0.083)$ & $0.806(0.103)$ & 5.4 & $(0.9-9.4)$ & $0.718(0.056)$ & $0.754(0.062)$ & 4.8 & $(2.5-6.5)$ & 0.220 \\
\hline LS BMC (g) & $22.7(6.2)$ & $25.0(9.2)$ & 10.2 & $(6.6-13.7)$ & $21.3(4.4)$ & $22.9(4.8)$ & 7.5 & $(5.6-9.4)$ & 0.343 \\
\hline LS BMD $\left(\mathrm{g} / \mathrm{cm}^{2}\right)$ & $0.674(0.123)$ & $0.705(0.150)$ & 4.6 & $(-1.7-8.3)$ & $0.645(0.079)$ & $0.678(0.090)$ & 5.3 & $(4.1-6.1)$ & 0.827 \\
\hline LS E (MPa) & 19.98 (11.53) & $20.28(4.8)$ & 1.5 & $(-4.9-7.6)$ & 19.30 (6.74) & $22.04(7.87)$ & 14.2 & $(10.4-20.4)$ & $0.039 *$ \\
\hline FN BMC (g) & 3.499 (0.759) & $3.741(0.952)$ & 6.8 & $(-1.0-13.7)$ & $3.355(0.487)$ & $3.553(0.596)$ & 5.9 & $(3.0-8.6)$ & 0.590 \\
\hline FN BMD $\left(\mathrm{g} / \mathrm{cm}^{2}\right)$ & $0.803(0.116)$ & $0.843(0.134)$ & 5.1 & $(1.5-9.1)$ & $0.777(0.076)$ & $0.812(0.081)$ & 4.5 & $(3.4-5.7)$ & 0.589 \\
\hline
\end{tabular}

Abbreviations: $\mathrm{CI}$ = Confidence interval; BMC = bone mineral content; BMD = bone mineral density; FN = femoral neck; LS = lumbar spine; WB = whole body; E $=$ material stiffness - Young's modulus. P values represent between-group comparison of percent change. $*=p \leq 0.05$. 
TABLE 4: BASELINE AND NINE-MONTH MEASURES $( \pm \mathrm{SD})$ WITH PERCENT CHANGE AND 95\% CONFIDENCE INTERVAL IN TIBIA AND RADIUS PQCT MEASURES $(\mathrm{N}=36)$.

\begin{tabular}{|c|c|c|c|c|c|c|c|c|c|}
\hline \multirow{2}{*}{ Parameter } & \multicolumn{4}{|c|}{ Control $(n=6)$} & \multicolumn{5}{|c|}{ Intervention $(n=30)$} \\
\hline & Baseline & Follow up & $\%$ & $95 \% \mathrm{CI}$ & Baseline & Follow up & $\%$ & $95 \% \mathrm{CI}$ & $\mathbf{p}$ \\
\hline Tibial total content 38\% (mg) & $240.65(36.80)$ & $259.24(61.18)$ & 7.7 & $(-10.3-15.8)$ & $225.82(48.51)$ & $239.85(59.69)$ & 5.6 & $(-5.1-12.0)$ & 0.606 \\
\hline Tibial trabecular content 38\% (mg) & $165.78(27.46)$ & $169.87(48.07)$ & 2.5 & $(-13.81-10.1)$ & $156.47(41.88)$ & $169.62(50.49)$ & 8.4 & $(-5.1-20.1)$ & 0.994 \\
\hline Tibial cortical content 38\% (mg) & $231.21(46.97)$ & 266.58 (84.87) & 12.3 & $(9.2-17.1)$ & $195.59(29.03)$ & $232.56(31.51)$ & 9.3 & $(6.7-11.7)$ & 0.305 \\
\hline Tibial cortical area 38\% $\left(\mathrm{mm}^{2}\right)$ & $225.44(67.1)$ & $238.75(63.08)$ & 11.2 & $(10.0-18.5)$ & $192.48(29.60)$ & $209.66(30.53)$ & 9.7 & $(7.0-12.5)$ & 0.497 \\
\hline Tibial periosteal circumference 38\% (mm) & $63.11(7.81)$ & $66.67(8.69)$ & 5.2 & $(4.4-6.7)$ & $58.40(4.97)$ & $60.74(4.84)$ & 4.3 & $(3.0-5.5)$ & 0.229 \\
\hline Tibial endosteal circumference 38\% (mm) & $31.56(4.59)$ & $32.54(4.37)$ & 2.3 & $(0.5-4.1)$ & $34.53(2.36)$ & $35.32(2.02)$ & 3.4 & $(1.5-5.3)$ & 0.784 \\
\hline Radial total content 66\% (mg) & $49.33(7.89)$ & $53.64(9.06)$ & 8.6 & $(2.9-14.4)$ & $50.10(12.82)$ & $56.54(14.54)$ & 16.9 & $(9.0-24.8)$ & 0.520 \\
\hline Radial trabecular content 66\% (mg) & $29.45(7.45)$ & $35.56(9.91)$ & 20.8 & $(-9.9-51.6)$ & 26.95 (10.73) & $33.43(11.04)$ & 45.0 & $(10.3-80.4)$ & 0.861 \\
\hline Radial cortical content 66\% (mg) & $48.49(13.21)$ & $49.49(5.76)$ & 1.4 & $(-11.4-13.8)$ & $42.42(9.12)$ & $48.42(9.63)$ & 16.5 & $(9.8-23.2)$ & 0.117 \\
\hline Radial cortical area $66 \%\left(\mathrm{~mm}^{2}\right)$ & $53.00(6.87)$ & $55.08(3.71)$ & 7.7 & $(-8.9-14.5)$ & $43.67(7.98)$ & $49.10(9.07)$ & 12.4 & $(6.0-19.7)$ & 0.083 \\
\hline Radial periosteal circumference 66\% (mm) & $36.20(2.39)$ & $37.93(1.46)$ & 4.8 & $(-1.3-18.1)$ & $30.68(4.21)$ & $33.21(3.84)$ & 9.2 & $(8.5-15.1)$ & $0.030 *$ \\
\hline Radial endosteal circumference 66\% (mm) & $24.51(2.30)$ & $25.47(3.31)$ & 3.9 & $(-8.5-17.1)$ & $20.21(4.67)$ & $23.13(3.74)$ & 14.4 & $(8.5-35.1)$ & 0.289 \\
\hline
\end{tabular}

Abbreviations: $\mathrm{CI}=$ Confidence interval. $\mathrm{P}$ values represent between-group comparison of percent change. ${ }^{*}=\mathrm{p} \leq 0.05$. 
Fig. 1. CONSORT diagram of participant flow.

Fig. 2. Nine-month change (\%) in calcaneal BUA, waist circumference, maximal vertical jump, resting heart rate and estimated $\mathrm{VO}_{2}$ max for CON (black) and EX (grey).

BUA = Broadband ultrasound attenuation; $\mathrm{VO}_{2} \max =$ maximal oxygen consumption.

Error bars indicate \pm SEM. 